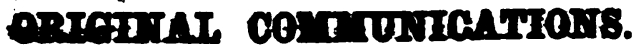

\section{OBSERVATIONS ON THE DEVELOPMENT OF O8ONE, AND A DEOXIDISING PROPERTY IN THE ATMOSPHERE.}

By T. SHAPTER, M.D., Physician to the Devon and Exeter Hospital.

Prosmeoor Sonörserr, the discoverer of ozone, has shown, by a series of the most convincing experiments, that the allotropic condition of exygen to which this term has bees applied possesses qualities of the highest importance, and that many phenomena with which we have long been familiar are due to its agency. The conclusions absolutely arrived at regarding the properties of this agent have induced Professor Sehönbein likewise to infer that it may exert very important infleences on the animal economy, and may probebly be a means of very materially inducing or modifying diseased actions.

In order to satisfy himself upon these points, he has sought to procure, from distant parts of the globe, simultaneous and corresponding observations on the daily development of this agent in the atmosphere. Through the intervention of Drs. Moffat and Drew, I have, in common with others, made during the last few months the required observations.

In the course of doing this, it has appeared to me that the mode proposed, while it has fully succeeded in marking the development of this agent, has failed to indicate another and equally interesting quality of the atmosphere, whether this be due to further properties of ozone, or to some other constituent or quality of the atmosphere.

The directions for noting and measuring the presence of ozone are very simple, being the free exposure to the atmosphere (protected from the direct rays of the sun and from rain) of a dry bibulous paper, previously saturated with a solution of starch, and a neutral iodide of potassium. The discolouring of this paper, when dry, to a brownish tint, and, if wetted, to a blue tint, constitutes the proof of the existence, and becomes the measurer, of the amount or intensity of the ozone developed; these changes in the paper being effected by the iodine being set free through its porrer of oxidising the potassium of the iodide. It will be at once seen that this is a test which has reference solely to the existence of an agent aeting positively in one direction, that is, as an oxidiser; nor do I understand from the observations made upon ozone, whether by Schönbein or by Faraday, that it is considered to have any other powers: whether derived from chemical agency, from electricity, or from the atmosphere, ozone is spoken of and shown to be ${ }^{*} a$ most ready and powerful oxydiser, and in a great number of cases acts like Thenard's peroxide of hydrogen, or ehlorine, or bromine."

In the course of the observations made with the ozonometer prepared and carried out in accordance with Schönbein's directions, I hare seen reason to believe that a property is at times developed in the atmosphere, whether due to ozone or not, which is directly opposed to that attributed to, and mainly characteristic of, ozone; that, in fact, there are grounds for concluding, from the evidence afforded by the iodine test, that there is developed in the atmosphere, at certain periods, a deoridising property, as well as, at other periods, an oxidising property.

In proof of this conclusion, I have, on very many occaions, observed that a test-paper which, by exposure, has been discoloured by the oxidising qualities of the ozone, has within a few hours afterwards had this discolouration discharged, to, perhaps, reacquire it on further exposure.

I will briefly detail a few instances of the oceurrence of these phenomens.

On the 6th of June, at.9.$x_{\text {, }}$ the test-paper was dis coloured to an intenaity correoponding to 5 upon the scale A the onemeter. Within them houm, this perper became entirely decoloured; in the after part of the same day, it was again discoloured to 3 , to be again blewehed by 9 A.se.

From this date till the 8th of June, there was no discolouration of the test-paper, when, at 9 P.M., it was discoloured to 6, which colour was entirely discharged by the following morning. From the 10th to the 14th of June, there were presented considerable indications of the development of ozone; on the evening of this day, its intensity was noted at 6; by the following morning, this had diminished to 2 . From the 17th to the 19th of June, there was another period in which the development of ozone was somewhat active. In the morning of this latter day, its intensity was noted at 7 ; in the afternoon, it was observed to have diminished to 4 ; and by 9 P.M., all colour was discharged. A few days previously to the 28 th of June, there had been a very considerable amount of ozone developed. At 9 A.M. on that day, it was noted at 8 ; by 9 P.M., this same paper had almost entirely lost all colour, being noted at 1 . On the 21st of this present month (July), similar phenomena were observed.

From the above, it will be seen that if, on the one hand, the test-paper is held to be conclusire evidence of the presence, at times, of a free oxidising agent in the atmosphere, so must it, on the other hand, be held to be an equally conclusive evidence of the presence, at other times, of a free deoxidising agent.

It might probably be objected that this discharging of the test colour was due to the bleaching power of the atmosphere; but it must be recollected that the colour produced is really due to, and is the evidence of, the presence of ozone, to which the bleaching quality of the atmosphere is attributed; and that the more this quality is developed, the more intensely is the test-paper discoloured. Nor is this discharging of colour in any way due to the test-paper becoming effete by exposure during a few hours to the atmosphere; for it must be particularly horne in mind that, if the development of ozone be maintained, the test-paper likewise accumulates its intensity of colour-a fact of some importance in observing the development of this agent.

I can scarcely venture to advance the opinion that oxygen, under two distinct forms of allotropism, becomes endowed with the opposite qualities of an oxygeniser and a deoxygeniser; for I can scarcely think, did it possess these, that Professor Schönbein would have overlooked their existence. Nerertheless, analogous effects are afforded by the phenomena of electricity in its negative and positive qualities.

Be this as it may, the facts remain that the ozone testpapers are, during certain seasons, so discoloured as to indicate the presence of an acid principle, while, at others, the opposite state is indicated by the discoloration thus produced being reabsorbed and entirely discharged. There is, therefore, ample ground for concluding that, if this double property of the atmosphere do not belong to that allotropic form of oxygen to which the term of ozone has been applied, there must exist either some other form of this same agent, or some other and distinct agent to which the phenomena of deoxidising belons.

Further observations may probably determine this point; and I would here suggest that, towards ascertaining the laws regulating these several qualities of the atmosphere, there be added to the test-papers at present used a coloured series, whereby may be noted the deoxidising as well as the oxydising qualities of the atmosphere.

I forbear at this time from making any remarks on the concurrence of the development of ozone with other atmospheric phenomena, or on the probable or surmised influence which this agent may exert on the animal economy. My observations, which extend over a period of eight months only, are far too limited to permit anything like a deduction of accurate or even probable conclusions.

kxeter, Augast 1854. 